\title{
Perspective Piece \\ Where Shared Sanitation is the Only Immediate Option: A Research Agenda for Shared Sanitation in Densely Populated Low-Income Urban Settings
}

\author{
James B. Tidwell, ${ }^{1,2 \star}$ Jenala Chipungu, ${ }^{3}$ lan Ross, ${ }^{4}$ Prince Antwi-Agyei, ${ }^{5,6}$ Mahbub-Ul Alam, ${ }^{7}$ Innocent K. Tumwebaze ${ }^{8}$ \\ Guy Norman, ${ }^{9}$ Oliver Cumming, ${ }^{4}$ and Sheillah Simiyu ${ }^{10}$ \\ ${ }^{1}$ World Vision Inc., Washington, District of Columbia; ${ }^{2}$ Harvard Kennedy School of Government, Cambridge, Massachusetts; ${ }^{3}$ Centre for Infectious \\ Disease Research in Zambia, Lusaka, Zambia; ${ }^{4}$ London School of Hygiene and Tropical Medicine, London, United Kingdom; ${ }^{5} \mathrm{NHance}$ \\ Development Partners Ltd, Kumasi, Ghana; ${ }^{6}$ University of Energy and Natural Resources, Sunyani, Ghana; ${ }^{7}$ International Centre for Diarrhoeal \\ Disease Research in Bangladesh, Dhaka, Bangladesh; ${ }^{8}$ Temple University, Philadelphia, Pennsylvania; ${ }^{9}$ Urban Research, Guildford, United \\ Kingdom; ${ }^{10}$ African Population and Health Research Center, Nairobi, Kenya
}

\begin{abstract}
Shared sanitation is not currently accepted within the international normative definitions of "basic" or "safely managed" sanitation. We argue that pro-poor government strategies and investment plans must include high-quality shared sanitation as an intermediate step in some densely populated urban areas. User experience must be considered in establishing the definition of high quality. We call for additional research on effective interventions to reach these quality standards and for the development of rigorous measures applicable to global monitoring.
\end{abstract}

\section{INTRODUCTION}

Sustainable Development Goal (SDG) target 6.2 calls for universal access to safely managed sanitation by 2030 , defined as "the use of an improved sanitation facility which is not shared with other households and where excreta is safely disposed in situ or transported and treated off-site." Meeting this target in a rapidly urbanizing world with densifying urban spaces $^{1}$ is profoundly challenging. Globally, $24 \%$ of urban dwellers live in informal settlements, ${ }^{2}$ characterized by poor housing quality, infrastructure, and services along with high population density, ${ }^{3}$ leading to poorer health outcomes than rural or formal urban areas. ${ }^{4}$ Residents in these contexts are a major contributor to the large and growing reality of shared sanitation use globally, with the number of users increasing from 249 million in 1990 to 603 million in $2015 .^{5}$

Sanitation shared by more than one household is not considered to meet the SDG standard of either basic or safely managed sanitation under current WHO/UNICEF Joint Monitoring Programme for Water and Sanitation definitions. ${ }^{6}$ Shared sanitation comprises a range of technologies and management/user models, ranging from toilets shared by a small number of neighboring households to public toilets used on occasion by thousands of people. These facilities may be categorized by location, physical or social aspects of access, size, and models of ownership, management, or payment. ${ }^{7}$ Acceptability varies greatly across these many types of shared sanitation, although here we restrict our focus to shared household sanitation (i.e., not public toilets).

A systematic review in 2014 did not support the inclusion of shared sanitation in general as "improved" under the Millennium Development Goals, ${ }^{8}$ although it concluded that existing evidence was limited and of poor quality. A subsequent multicountry study with focus on moderate to severe diarrhea in children found that shared sanitation use was generally associated with higher disease risk but found it to be protective in some settings. ${ }^{9}$ Other recent studies have reported that toilets shared exclusively between neighbors are more

*Address correspondence to James B. Tidwell, World Vision Inc., 300 I St. NE, Washington, DC 20002. E-mail: btidwell@worldvision.org protective against diarrhea than public/communal toilets. ${ }^{10}$ Shared toilets may also be of higher structural quality than private toilets ${ }^{11}$ and have similar levels of fecal contamination, $^{12}$ although they may be less clean because more households share them. ${ }^{13}$ However, in India, some professionally managed public toilet blocks were found to be acceptable to users, and effluent was safely managed. ${ }^{14} \mathrm{Im}$ proving the quality of shared sanitation alone in high-density urban settings may only have a limited impact on health, given the pervasive contamination. ${ }^{15}$ Given that the use of these shared facilities was high, there is no reason to assume that non-shared, household-level facilities would have had a greater health impact, and poor waste management, ${ }^{16}$ child feces, ${ }^{17}$ and animal feces ${ }^{18}$ mean that many other sources of contamination are present.

In 2017, a call for further consideration of shared sanitation under the SDGs argued that ignoring the possibility of acceptable shared sanitation might limit investment in informal urban settlements. ${ }^{19}$ Some city sanitation master plans specifically mentioned the inclusion of shared, on-site sanitation because of its meeting the proposed SDG indicators at the time. $^{20}$ The SDGs themselves called for intermediate steps and reducing inequalities, advocating for "prioritizing investments in high-quality shared toilets where it is the only viable option for improving sanitation services." 19 As new interdisciplinary research emerges on the topic of shared sanitation in low-income unplanned urban areas, we convened a symposium at the 2019 University of North Carolina Water and Health Conference to map out a potential research agenda.

Although private household sanitation remains the normative global standard and the preferred option for most users, in some settings, shared sanitation exists as a short- to mediumterm necessity. ${ }^{21}$ The aim of this symposium was to set out a research agenda that would support effective policy and practice on shared sanitation in urban settings where this is currently considered the only option. We considered three aspects: how users experience shared sanitation, how we can improve its quality, and how we can define and measure highquality sanitation.

Setting and user experiences. In most low-income areas, there is often little space for private household sanitation 
facilities, whether inside the dwelling or outside. Shared household sanitation services in low-income settlements are often on-site facilities provided by landowners, some of whom reside within the settlements. ${ }^{22,23}$ Landowners usually prioritize construction of rental units over sanitation facilities, thinking they are the better investment, thus forcing tenants to continue sharing the few available sanitation facilities. Insecurity of tenure in some settlements also contributes to substandard housing and sanitation facilities. ${ }^{23,24}$ When toilets are not provided or are of low quality, residents sometimes also access pay-per-use public toilets and may use many different sanitation facilities regularly even if they are provided a high-quality toilet at home. ${ }^{25}$ However, factors such as distance, cleanliness, cost, and operating hours influence the use of public toilet facilities. ${ }^{10,26,27}$ In addition, the lack of access or access to low-quality sanitation facilities also poses a greater challenge to vulnerable populations, such as women, the elderly, people with disabilities, and children. ${ }^{28,29}$

In rented accommodation, landlords usually have responsibility for sanitation provision, whereas tenants take responsibility for cleaning. ${ }^{24}$ Operation and maintenance costs and responsibilities are sometimes taken up entirely by landlords or shared between landlords and tenants. Shared sanitation facilities are often dirty because of limited participation in cleaning, especially when there are many users, ${ }^{13,30,31}$ experiencing the same challenges as management of any common-pool resources whose maintenance depends on actions of other users. ${ }^{31,32}$ The uncleanliness and lack of participation in cleaning lead to dissatisfaction among the users of shared sanitation facilities, ${ }^{33}$ disagreements and conflicts among users, ${ }^{31,32}$ and psychological stress, ${ }^{34}$ and in extreme cases, users can opt to use alternatives such as open defecation or "flying toilets." ${ }^{35}$ User commitment and social capital are critical for successful collective management of shared sanitation facilities, including the need to strengthen communication and accountability between landlords and tenants. ${ }^{32,36-38}$ Our suggested priority research questions for the setting and user experience are as follows:

1. What kinds of experiences do users, and especially women, children, and those with disabilities, have with different kinds of shared sanitation?

2. What are the key drivers of demand for improving the quality of shared sanitation?

3. How can we assess the impact of shared sanitation quality on user experience?

4. What is the impact of improvements in the structural quality and management systems on the overall physical and mental well-being of shared sanitation users?

Effective interventions. Shared sanitation interventions generally target one or both of two key results: the cleanliness of facilities and improving structural quality through new construction or modification of existing facilities. Shared cleaning has been promoted through direct-to-household behavior change communication focused on flushing toilets, solid waste disposal, and use of a potty to collect child feces, along with the provision of water pouring cups and storage containers. ${ }^{39}$ Beyond this individual focus, other interventions have addressed social dilemmas and collective action problems around shared cleaning. In Uganda, meetings were held between landlords and tenants to discuss challenges and make commitments to cleaning by creating a sense of cleaning obligation, ease, approval, and changing affective beliefs. ${ }^{40}$ In Zambia, because of the challenges of high turnover of tenants and the existing system of verbal, daily rota turns being hard to manage, a new system was introduced to improve cleaning. ${ }^{41}$ A weekly rota system was promoted with a "symbol of responsibility" hanging above the door of the responsible tenant so that they were accountable for any failure to clean, resolving the key management challenge and signaling social norms to new residents without the need for whole-of-plot meetings.

Infrastructure improvement has been attempted through assessing tenant willingness to pay for better sanitation through increased rent ${ }^{41}$ and then leveraging that via emotional demonstrations and games to help landlords decide to intentionally improve sanitation quality. ${ }^{41}$ Although this approach was successful, potentially because in the study area, $42 \%$ of landlords initially thought that tenants were not willing to pay for anything beyond a basic sanitation service, communicating latent demand may only be the first step in the process of improving infrastructure quality. Some gains have also been observed by providing loans ${ }^{42}$ or subsidies, ${ }^{43,44}$ promoting regulatory enforcement ${ }^{45}$ and legal approaches ${ }^{46}$ to solving tenure challenges and through coproduction and collective action among residents. ${ }^{47}$ We suggest the following priority research questions on designing effective interventions:

5. What are the most effective management systems for different kinds of shared sanitation?

6. What combination and/or sequencing of market-based approaches, financial products, regulatory and legal frameworks, and collective action/coproduction is needed to drive sustainable improvements in shared sanitation quality?

Measurement and monitoring. Measurement of different aspects of shared sanitation quality is important for routine monitoring by service providers to global monitoring by the WHO/UNICEF Joint Monitoring Programme for Water and Sanitation to rigorous impact evaluation. Using a sanitation quality index and toilet cleanliness index, a study of Quality Indicators for Shared Sanitation in three countries found that reliance on improved technology type and toilet sharing may not serve as an adequate indicator of toilet cleanliness or overall toilet quality. Preliminary findings from this study show that in addition to toilet technology and sharing, other factors such as the location of the toilet, whether the door has a lock and whether the floor is tiled, significantly influence overall toilet quality. ${ }^{48}$ Characteristics of sanitation infrastructure can be objectively and rapidly measured, and structural quality had more of an impact on observed cleanliness and reported satisfaction than cleaning behavior in a study in Zambia. ${ }^{49}$ However, measuring infrastructure alone is insufficient. Two users, for example, an adolescent girl and a middle-aged man, may experience the same toilet very differently. Assessment of user experience and qualityof-life impacts may be required in many cases. Work is ongoing in urban Mozambique to develop a measure of sanitation-related quality of life, which captures the extent of achievement of outcomes most valued by users. ${ }^{50}$ For rural areas, Caruso et al. ${ }^{51}$ developed an experiential measure of women's sanitation insecurity, conceptualized as an 
exposure, rather than an outcome. It was subsequently used to show that latrine access was associated with higher mental well-being. ${ }^{52}$

Those who fund, design, monitor, and evaluate programs require simple validated measures that can be applicable across settings, whether for infrastructure quality or userreported outcomes. Many measures mentioned earlier have been developed and/or applied in only one setting thus far and insufficiently consider outcomes further down the service chain. We suggest the following priority research questions around measurement and monitoring:

7. What easy-to-use measures of shared sanitation quality can be validated and applied across multiple settings?

8. How can user experience evaluations be used to make judgments about the quality of different types of shared sanitation and of shared sanitation interventions?

9. What additional measures are needed to understand the impacts of different kinds of sanitation further down the service chain-for example, regarding pathogen exposures and/or quality of life of sanitation workers? ${ }^{53}$

\section{CONCLUSION}

In many settings, private household sanitation is a distant prospect. So, understanding the conditions under which highquality shared sanitation leads to positive user experiences, seeking to improve these conditions, and developing rigorous measures may lead to adequate prioritization of higher quality shared sanitation in dense urban areas. Therefore, we suggest a final research question to be added to the agenda:

10. How can we promote the prioritization of improving the quality of shared sanitation in these dense urban contexts?

Received August 9, 2020. Accepted for publication September 29, 2020.

Published online November 16, 2020.

Financial Support: This work was partly funded by UKAID through the SHARE Research Consortium.

Authors' addresses: James B. Tidwell, World Vision Inc., Washington, DC, and Harvard Kennedy School of Government, Havard, MA, E-mail: btidwell@worldvision.org. Jenala Chipungu, Centre for Infectious Disease Research in Zambia, Lusaka, Zambia, E-mail: jenala.chipungu@cidrz.org. lan Ross and Oliver Cumming, London School of Hygiene and Tropical Medicine, London, United Kingdom, E-mails: ian.ross@Ishtm.ac.uk and oliver.cumming@Ishtm.ac.uk. Prince Antwi-Agyei, NHance Development Partners Ltd, Kumasi, Ghana, and University of Energy and Natural Resources, Sunyani, Ghana, E-mail: prince.antwi-agyei@uenr.edu.gh. Mahbub-UI Alam, International Center for Diarrhoeal Disease Research in Bangladesh, Dhaka, Bangladesh, E-mail: mahbubalam@icddrb.org. Innocent K. Tumwebaze, Temple University, Philadelphia, PA, E-mail: kamara.innocent@gmail.com. Guy Norman, Urban Research, Guildford, United Kingdom, E-mail: guy.norman.mail@gmail.com. Sheillah Simiyu, African Population and Health Research Center, Nairobi, Kenya, E-mail: ssimiyu@aphrc.org.

This is an open-access article distributed under the terms of the Creative Commons Attribution (CC-BY) License, which permits unrestricted use, distribution, and reproduction in any medium, provided the original author and source are credited.

\section{REFERENCES}

1. Dijkstra L, Florczyk A, Freire S, Kemper T, Pesaresi M, Schiavina M, 2018. Applying The Degree Of Urbanisation To The Globe: A New Harmonised Definition Reveals A Different Picture Of Global Urbanisation. Proceedings of the 16th IAOS Conference: Better Statistics for Better Lives, September 19-21, 2018, Paris, France.

2. United Nations, 2019. Sustainable Development Goals Report 2019. New York, NY: United Nations.

3. UN-HABITAT, 2003. The Challenge of Slums: Global Report on Human Settlements. Nairobi, Kenya: United Nations Human Settlements Programme.

4. Ezeh A, Oyebode O, Satterthwaite D, Chen YF, Ndugwa R, Sartori J, Mberu B, Melendez-Torres G, Haregu T, Watson SI, 2017. The history, geography, and sociology of slums and the health problems of people who live in slums. Lancet 389: 547-558.

5. UNICEF, WHO, 2015. Progress on Sanitation and Drinking Water2015 Update and MDG Assessment. Geneva, Switzerland: World Health Organization.

6. WHO, UNICEF, 2017. Progress on Drinking Water, Sanitation and Hygiene: 2017 Update and SDG Baselines. Geneva, Switzerland: World Health Organization.

7. Mazeau A, Reed B, Sansom K, Scott R, 2014. Emerging categories of urban shared sanitation. Water Environ J 28:592-608.

8. Heijnen M, Cumming O, Peletz R, Chan GK, Brown J, Baker K, Clasen T, 2014. Shared sanitation versus individual household latrines: a systematic review of health outcomes. PLoS One 9: e93300.

9. Baker KK et al., 2016. Sanitation and hygiene-specific risk factors for moderate-to-severe diarrhea in young children in the global enteric multicenter study, 2007-2011: case-control study. PLOS Med 13: e1002010.

10. Heijnen M, Routray P, Torondel B, Clasen T, 2015. Neighbourshared versus communal latrines in urban slums: a crosssectional study in Orissa, India exploring household demographics, accessibility, privacy, use and cleanliness. Trans $R$ Soc Trop Med Hyg 109: 690-699.

11. Jenkins MW, Cumming O, Scott B, Cairncross S, 2014. Beyond 'improved' towards 'safe and sustainable' urban sanitation: assessing the design, management and functionality of sanitation in poor communities of Dar es Salaam, Tanzania. J Water Sanit Hyg Dev 4: 131.

12. Exley JLR, Liseka B, Cumming O, Ensink JHJ, 2015. The sanitation ladder, what constitutes an improved form of sanitation? Environ Sci Technol 49: 1086-1094.

13. Günther I, Niwagaba CB, Luthi C, Horst A, Mosler HJ, Tumwebaze IK, 2012. When is shared sanitation improved sanitation? - the correlation between number of users and toilet hygiene. Research for Policy, Vol. 2, Zurich, Switzerland: ETH Zurich.

14. Burra S, Patel S, Kerr T, 2003. Community-designed, built and managed toilet blocks in Indian cities. Environ Urban 15: 11-32.

15. Holcomb DA, Knee J, Sumner T, Adriano Z, de Bruijn E, Nalá R, Cumming O, Brown J, Stewart JR, 2020. Human fecal contamination of water, soil, and surfaces in households sharing poor-quality sanitation facilities in Maputo, Mozambique. Int $J$ Hyg Environ Health 226: 113496.

16. Amin N, Liu P, Foster T, Rahman M, Rana M, Moe CL, Willetts J, 2020. Pathogen flows from sanitation systems in Dhaka: a quantitative environmental assessment. Int $\mathrm{J}$ Hyg Environ Health 230: 113619 .

17. Majorin F, Torondel B, Chan GKS, Clasen T, 2019. Interventions to improve disposal of child faeces for preventing diarrhoea and soil-transmitted helminth infection. Cochrane Database Syst Rev 9: CD011055.

18. Budge S, Hutchings P, Parker A, Tyrrel S, Tulu T, Gizaw M, Garbutt C, 2019. Do domestic animals contribute to bacterial contamination of infant transmission pathways? Formative evidence from Ethiopia. J Water Health 17: 655-669.

19. Evans B, Hueso A, Johnston R, Norman G, Pérez E, Slaymaker T, Trémolet S, 2017. Limited services? The role of shared sanitation in the 2030 Agenda for sustainable development. $J$ Water Sanitation Hyg Development 7: 349-351.

20. World Bank, 2015. PRA for Lusaka Sanitation Project, 83. Washington DC: World Bank. 
21. Schouten MAC, Mathenge RW, 2010. Communal sanitation alternatives for slums: a case study of Kibera, Kenya. Phys Chem Earth, Parts A/B/C 35: 815-822.

22. Tidwell JB, Chipungu J, Chilengi R, Curtis V, Aunger R, 2018. Theory-driven formative research on on-site, shared sanitation quality improvement among landlords and tenants in periurban Lusaka, Zambia. Int J Environ Health Res 29: 312-325.

23. Scott $P$, Cotton A, Sohail Khan M, 2013. Tenure security and household investment decisions for urban sanitation: the case of Dakar, Senegal. Habitat Int 40: 58-64.

24. Isunju JB, Schwartz K, Schouten MA, Johnson WP, van Dijk MP, 2011. Socio-economic aspects of improved sanitation in slums: a review. Public Health 125: 368-376.

25. Foggitt E, Cawood S, Evans B, Acheampong P, 2019. Experiences of shared sanitation-towards a better understanding of access, exclusion and 'toilet mobility'in low-income urban areas. J Water Sanit Hyg Dev 9: 581-590.

26. Simiyu S, 2016. Determinants of usage of communal sanitation facilities in informal settlements of Kisumu, Kenya. Environ Urban 28: 241-258.

27. Biran A, Jenkins MW, Dabrase P, Bhagwat I, 2011. Patterns and determinants of communal latrine usage in urban poverty pockets in Bhopal, India. Trop Med Int Health 16: 854-862.

28. Ritter $\mathrm{RL}$ et al., 2018. Within-compound versus public latrine access and child feces disposal practices in low-income neighborhoods of Accra, Ghana. Am J Trop Med Hyg 98: 1250-1259.

29. Mactaggart I et al., 2018. Access to water and sanitation among people with disabilities: results from cross-sectional surveys in Bangladesh, Cameroon, India and Malawi. BMJ Open 8: e020077.

30. Tumwebaze IK, 2014. Prevalence and determinants of the cleanliness of shared toilets in Kampala slums, Uganda. J Public Health 22: 33-39.

31. Simiyu S, Swilling M, Cairncross S, Rheingans R, 2017. Determinants of quality of shared sanitation facilities in informal settlements: case study of Kisumu, Kenya. BMC Public Health 17: 68 .

32. Chipungu J, Tidwell JB, Chilengi R, Curtis V, Aunger R, 2018. The social dynamics around shared sanitation in an informal settlement of Lusaka, Zambia. J Water Sanit Hyg Dev 9: 102-110.

33. Tumwebaze IK, Orach CG, Niwagaba C, Luthi C, Mosler HJ, 2013. Sanitation facilities in Kampala slums, Uganda: users' satisfaction and determinant factors. Int J Environ Health Res 23: 191-204.

34. Shiras T, Cumming O, Brown J, Muneme B, Nala R, Dreibelbis R, 2018. Shared latrines in Maputo, Mozambique: exploring emotional well-being and psychosocial stress. BMC Int Health Hum Rights 18: 30.

35. Kwiringira J, Atekyereza P, Niwagaba C, Gunther I, 2014. Descending the sanitation ladder in urban Uganda: evidence from Kampala Slums. BMC Public Health 14: 624

36. Shiras T, Cumming O, Brown J, Muneme B, Nala R, Dreibelbis R, 2018. Shared sanitation management and the role of social capital: findings from an urban sanitation intervention in Maputo, Mozambique. Int J Environ Res Public Health 15: 2222.

37. Tumwebaze IK, Mosler HJ, 2014. Shared toilet users' collective cleaning and determinant factors in Kampala slums, Uganda. BMC Public Health 14: 1260.

38. Tumwebaze IK, Mosler HJ, 2014. Why clean the toilet if others don't? Using a social dilemma approach to understand users of shared toilets' collective cleaning behaviour in urban slums: a review. J Water Sanit Hyg Dev 4: 359-370.
39. Alam MU et al., 2017. Behaviour change intervention to improve shared toilet maintenance and cleanliness in urban slums of Dhaka: a cluster-randomised controlled trial. Trop Med Int Health 22: 1000-1011.

40. Tumwebaze IK, Mosler HJ, 2015. Effectiveness of group discussions and commitment in improving cleaning behaviour of shared sanitation users in Kampala, Uganda slums. Soc Sci Med 147: 72-79.

41. Tidwell JB, Chipungu J, Bosomprah S, Aunger R, Curtis V, Chilengi $R, 2019$. Effect of a behaviour change intervention on the quality of peri-urban sanitation in Lusaka, Zambia: a randomised controlled trial. Lancet Planet Health 3: e187-e196.

42. Ben Yishay A, Fraker A, Guiteras R, Palloni G, Shah NB, Shirrell S, Wang P, 2017. Microcredit and willingness to pay for environmental quality: evidence from a randomized-controlled trial of finance for sanitation in rural Cambodia. $J$ Environ Econ Manage 86: 121-140.

43. Guiteras R, Levinsohn J, Mobarak AM, 2015. Sanitation subsidies. Encouraging sanitation investment in the developing world: a cluster-randomized trial. Science 348: 903-906.

44. Guiteras R, Levinsohn J, Mobarak M, 2018. Demand Estimation with Strategic Complementarities: Sanitation in Bangladesh. CEPR Discussion Paper No. DP13498. Washington DC: Center for Economic and Policy Research.

45. Antwi-Agyei P, Monney I, Dwumfour-Asare B, Cavill S, 2019. Toilets for tenants: a cooperative approach to sanitation byelaw enforcement in Ga West, Accra. Environ Urban 31: 293-308.

46. Scott $P$, Cotton A, Sohail M, 2015. Using tenure to build a "sanitation cityscape": narrowing decisions for targeted sanitation interventions. Environ Urban 27: 389-406.

47. McGranahan $\mathrm{G}, 2015$. Realizing the right to sanitation in deprived urban communities: meeting the challenges of collective action, coproduction, affordability, and housing tenure. World Dev 68: 242-253.

48. Schelbert $V$ et al., 2020. When is shared sanitation acceptable in low-income urban settlements - a user perspective on quality priorities in Kumasi, Kisumu, and Dhaka. J Water Sanit Hyg Dev, (In press) doi:10.2166/washdev.2020.084.

49. Tidwell JB, Chipungu J, Chilengi R, Aunger R, 2018. Assessing peri-urban sanitation quality using a theoretically derived composite measure in Lusaka, Zambia. J Water Sanit Hyg Dev 8: 668-678.

50. Brown $\mathrm{J}$ et al., 2015. A controlled, before-and-after trial of an urban sanitation intervention to reduce enteric infections in children: research protocol for the Maputo Sanitation (MapSan) study, Mozambique. BMJ Open 5: e008215.

51. Caruso BA, Clasen T, Yount KM, Cooper HL, Hadley C, Haardörfer R, 2017. Assessing women's negative sanitation experiences and concerns: the development of a novel sanitation insecurity measure. Int $J$ Environ Res Public Health 14: 755.

52. Caruso BA, Cooper HLF, Haardörfer R, Yount KM, Routray P, Torondel B, Clasen T, 2018. The association between women's sanitation experiences and mental health: a cross-sectional study in Rural, Odisha India. SSM Popul Health 5: 257-266.

53. Bischel HN, Caduff L, Schindelholz S, Kohn T, Julian TR, 2019. Health risks for sanitation service workers along a containerbased urine collection system and resource recovery value chain. Environ Sci Technol 53: 7055-7067. 